\title{
Research and Practice on the Teaching Mode of Geometrical Optics Based on the Engineering Education Accreditation
}

\author{
Chun-Hua REN ${ }^{1, a}$, Xiao-Ming $\mathrm{HU}^{2, \mathrm{~b},{ }^{*}}$ and Chao $\mathrm{GAO}^{3, \mathrm{c}}$ \\ ${ }^{1,2,3}$ College of Optoelectronic Engineering, Chongqing University \\ archht@163.com, b 759930229@qq.com, 'gaoc@cqu.edu.cn
}

\begin{abstract}
Keywords: higher education, measurement and control specialty, geometrical optics, teaching mode, engineering education accreditation..
\end{abstract}

\begin{abstract}
As the basic course of measurement and control technology and instrument specialty, geometric optics is one of the core courses to culture the student with a comprehensive ability of optics, machine, circuit and compute. Based on the cultivating objective of using geometry optics knowledge to solve measurement and control engineering problems of our specialty and the requirement of professional accreditation for engineering, aiming at the training target of technical personnel with the ability to solve complex engineering problems, the teaching method for geometrical optics is researched and analyzed. In the area of teaching content v teaching method and assessment method, three practical methods are proposed in this paper: diversification of teaching and learning models, micro subject based on the combination of curriculum content and specialty characteristic, and the diversification of assessment model.
\end{abstract}

\section{Introduction}

Geometrical optics is an important and practical subdiscipline, which is based on the study of light propagation and imaging [1-2]. The course is a basic degree course for the specialty of measurement and control technology and instrument. It aims at cultivating students' ability to analyze and solve the problems of geometrical optics in engineering field. For instance, theories of imaging, aberration and beam limiting have a wide range of applications in real life and scientific research [3-4].

It plays an important role in the teaching and learning system of the measurement and control specialty. At present, almost all of the measurement and control majors in colleges and universities in China have carried out the teaching of the course "geometrical optics". In order to conform to the trend of development of global science and technology, and make the higher education in China be in line with international standards, engineering accreditation has got a wide range of attention and recognition in recent years [5-7]. The professional certification put forward the requirement of "qualified graduate students should have the ability to solve complex engineering problems" in 2014.

In this paper, combined with the results of professional certifications in our college in recent years, the existing problems in our teaching models are summed up. Aiming at these problems, investigation and analysis are carried out. Combined with the characteristics of "geometrical optics", considering the training objectives of students majoring in measurement and control [8-10], suggestions in the area of teaching content, teaching methods and assessment methods are proposed respectively. Three points has been put forward: diversification of teaching and learning models, micro subject based on the combination of curriculum content and the specialty characteristic, and the diversification of assessment model. The proposed methods will be test through educational practice.

\section{Thinking on the Teaching of Geometrical Optics}

Aiming at the target of personnel training in measurement and control specialty, considering the actual situation of the professional certification in the past few years, this paper sums up the ideal teaching model of geometrical optics: In the process of teaching, the students should not be taught by instillation. In contrast, we should focus on cultivating students' active learning attitude. Students 
should be placed in the dominant position. Providing some engineering training for students is a good notion. Meanwhile, we should ensure that students can get adequate guidance and help in the process of active learning.

Based on the results of professional certification of measurement and control specialty in our college, combined with our own teaching experience, we summarize the following problems on the teaching of "geometrical optics" course in our college:

In the area of teaching content, there is too much attention which had been put on the explaining of the book theory. The part of practical application and technological frontier is accordingly reduced for a huge extent. What's more, the actual images matching the theory analysis are not enough, and the experiment of the course cannot achieve good results. From the aspect of teaching methods, the teaching form is mainly based on classroom teaching, which is pretty monotony. Thus, students' innovation consciousness and ability to solve problems cannot be cultivated effectively. When it comes to the evaluation methods, the combination of teaching methods and evaluation mechanism is not deep enough, assessment methods and evaluation methods are single, the evaluation of students' comprehensive ability is insufficient.

Established in the actual situation of the personnel training objectives of measurement and control specialty and the requirements of professional certification, suitable suggestion on the adjustment of teaching mode is proposed. The aim is to make the teaching mode adapt to the professional characteristics and the actual situation of the students, so as to cultivate the students' ability to study and solve practical engineering problems.

In view of the above three questions, practical solutions to the problems are put forward respectively, which includes the following three points:

Enrich the teaching mode and learning mode, increase the proportion of science and technology frontier and lectures. Diversify the teaching materials and teaching forms, organize class discussion regularly. The teacher designs the topic of the discussion in advance、 defines the basic problems to be solved, and guides the students to carry out diversified learning;

Based on the characteristics of measurement and control specialty, combine the course like "geometrical optics measurement" and "precision measurement and control" together to design the micro subject. The micro topic should include complex engineering problems, based on which the students carry out the discussion and design 、 literature review 、 theoretical analysis and data calculation as a group.

Using a variety of assessment methods, combine the written examination, group task and the defense together, through which the comprehensive quality and ability of the students can be evaluated effectively.

\section{Suggestions on the Teaching of Geometrical Optics}

\section{Enrich Teaching and Learning Method}

On the premise of ensuring the teaching of basic theory, the teaching emphasis should be placed on the horizontal and vertical extension of the curriculum. After strengthening the theoretical basis of students, the application and practice of curriculum content should be focused on. Meanwhile, in order to meet the demands of the personnel market and engineering technology companies, practical skills training with the specialty of measurement and control should be carried out. In these ways, the practicality of the course can be enhanced, and the students' engineering application ability can be cultivated. In addition, we should pay attention to the feedback of students, adjust the content and structure of the courseware according to the teaching effectiveness. To ensure the frontier of the course, achievements in scientific research should be integrated into the teaching content duly. 


\section{Micro Subject Based on the Combination of Curriculum Content and Specialty Characteristic}

The specialty of measurement and control technology and instrument in our institute aims to "train the technical talents with the spirit of cooperation and the ability to solve complex engineering problems". In this engineering application oriented teaching, we should not only focus on the basic principles and basic knowledge, but also pay attention to the engineering application, thus we can open up the application of knowledge. Therefore, while teachers teaching the basic content of the course, they should make the curriculum be closely related to the engineering application of measurement and control technology. In order to consolidate and strengthen students' understanding and mastery of knowledge, the practical problems which related to the course content should be integrated into classroom teaching.

Therefore, based on the characteristics of measurement and control specialty, this paper puts forward the form of micro topics. Micro topic is a relatively complex engineering problem, which combines the major courses like geometric optics and precision measurement and control. Teacher can guide the students (6 7person/group) to carry out the discussion, literature review, theoretical analysis, data calculation, and finally achieve the design of the system.

For example, while learning the chapter of "secondary reflection”, teacher can arrange a micro topic about the design of laser swinger system based on pentagonal prism. The basic principle of laser scanner is: A laser diode emits a laser beam through an objective lens, the direction of the laser beam is changed 90 degrees. The motor drives the rotating head of the instrument to rotate through the belt to form a scanning laser plane. The instrument is equipped with a long leveling instrument, which is used to ensure the instrument level. In the process of designing the system, the students put forward problems, consult documents, market survey, discuss in a team and solve them together, the complex engineering problem such as: install the laser generator and prism, parameter calculation ,drive the instrument rotating through the motor, the price, the demands of the market. Finally the system function of laser scanning device can be achieved. Through the practice of such a micro subject, the students can realize the complexity of the problem in practical engineering design, and their ability to solve physical problems can be cultivated effectively.

\section{Course Assessment}

More comprehensive and balanced teaching evaluation system for students should be taken. The evaluating indicators include three aspects.

One is based on the score of the teacher, the score include the students' classroom performance, group performance, after class exercises, small papers, integrated design and the written examination results. Set the weight factor of each item, and increase the weight of the micro project. By this method, students' initiative to explore and think about engineering problems can be developed. Carry out the "group discussion" as extended task, the reference topics of the discussions can be drew up according to the specific knowledge points in different sections of geometric optics. While teaching the corresponding chapters, put forward the relevant questions and inspire students to think. Meanwhile, students are encouraged to develop their own research topics according to what they have learned and what they have read. At the end of the semester, carry out thematic defense assessment, the whole class members participate in the voting, self assessment and mutual evaluation are conducted at the same time. Live scoring by the judges teacher should also be included.

The second is based on the student. Questionnaire method is adopted here. The content of the questionnaire mainly include the evaluation of the mastery of professional knowledge by student, the weak part, the teaching method a, the suggestion ,etc.

The third is based on the peer experts. At least five experts (two come from Chongqing University and three come from our college) participate in lectures and grading. They evaluate the teaching of the teacher and the performance of the students.

Finally, combined with the performance of the group discussion and the micro project, the final score can be calculated through weighted calculation. The assessment model not only inspects the 
students' thinking ability, develop their ability of expression and organization, so as to meet the course standards --“learn in order to practice, develop comprehensive quality”,but also inspects the teacher's teaching ability, so that help to improve teaching quality.

\section{Conclusion}

Based on the objective of cultivating practical talents, combined with the results of professional certifications in our college in recent years, the problems in the teaching mode of geometrical optics are proposed. Aiming at the training target of "technical personnel with the spirit of cooperation and the ability to solve complex engineering problems" in the training program, three practical methods are proposed in this paper: diversification of teaching and learning models v micro subject based on the combination of curriculum content and specialty characteristic, and the diversification of assessment model. Through a variety of teaching methods, we can cultivate students' active learning attitude, enhance students' ability to solve the engineering problems, and improve the students' comprehensive ability. The ultimate aim is to help students to transfer from public basic courses learning to engineering training, and accumulate their practical experience, thus they can make adequate preparation for work.

\section{References}

[1] Wilkinson, T. D. (2012). Geometric Optics. Springer Berlin Heidelberg.

[2] Luneburg, R. K., \& Herzberger, M. (1965). Modern geometric optics. (book reviews: mathematical theory of optics). Ubicomp Poster Proceedings, 1276-1277.

[3] Jia-Wen, X. U., Cheng, X. A., \& Zhong, H. R. (2016). Reflection and practice about teaching modes of applied optics course. Journal of Higher Education Research.

[4] Guo, R. H., \& Gao, Z. S. (2009). The improved teaching method on applied optics. Higher Education Forum.

[5] Zhang, W. L., Xiong, F. L., Xiang-Bin, Y. E., \& Luo, W. S. (2008). Research on the integrated optimization of the specialized curriculum system of measurement \& control technology and instrument specialty. Journal of Higher Education Research.

[6] Chen, R. Q., Qian, S. X., \& Xiao-Jun, G. U. (2013). Research on the integrated reform and optimization of the specialized curriculum system of measurement \& control technology and instrument specialty. Journal of Jiaxing University.

[7] Liu, X., Liu, J., \& Lu, J. (2011). Oilfield-oriented innovative talent training model of measure and control technology and instrument specialty.Value Engineering.

[8] Xie, Q., Dai, M., Xin, L. I., Chen, F., \& Qi-Min, G. U. (2013). Exploration of talents training of measurement and control technology and instrumentation specialty. Journal of Electrical \& Electronic Education,12(5), 425-430.

[9] Xie, Q., Benlian, X. U., Zhi-Chao, L. I., Dai, M., \& Xin, L. I. (2012). Exploration and practice of measurement and control technology and instrumentation specialty construction. Journal of Changshu Institute of Technology.

[10] Xie, Q., Benlian, X. U., Dai, M., Wei, X. U., \& Chen, F. (2014). Exploration and practice for construction of advanced measurement and control technology joint training center. Experiment Science \& Technology. 